\title{
Correction to: Adrenocortical carcinoma complicated by renal thrombotic microangiopathy, a case-series
}

Tristan de Nattes ${ }^{1 *}$, Lucile Moreau-Grangé2 ${ }^{2}$, Delphine Vezzosi ${ }^{3}$, Julien Hadoux ${ }^{4}$, Miguel Hie ${ }^{5}$, Dominique Guerrot ${ }^{1}$ and Steven Grangé ${ }^{6}$

\section{Correction to: BMC Nephrol https://doi.org/10.1186/s12882-020-1703-5}

Following publication of the original article [1], we have been notified that the name of one author was spelled incorrectly as Julien Haddoux, when the correct spelling is Julien Hadoux.

The original article has been corrected.

\author{
Author details \\ ${ }^{1}$ Nephrology - Kidney Transplant Unit, Rouen University Hospital, 76031 \\ Rouen, France. ${ }^{2}$ Endocrine Unit, Rouen University Hospital, Rouen, France. \\ ${ }^{3}$ Endocrine Unit, Toulouse University Hospital, Toulouse, France. ${ }^{4}$ Medical \\ Oncology Department, Gustave Roussy Institute, Villejuif, France. \\ ${ }^{5}$ Department of Internal Medicine, Pitie-Salpetriere Hospital, AP-HP, Paris, \\ France. ${ }^{6}$ Department of Medical Critical Care, Rouen University Hospital, \\ Rouen, France.
}

Published online: 10 February 2020

\section{Reference}

1. de Nattes, et al. Adrenocortical carcinoma complicated by renal thrombotic microangiopathy, a case-series. BMC Nephrol. 2020;21:35 https://doi.org/10. 1186/s12882-020-1703-5

Full list of author information is available at the end of the article 